time there was neither local nor general reaction. One of them was slaughtered and old-standing tubercles were found in the lungs. The other animal was kept for another twelve months and was then destroyed. Before its death a dose of mallein was injected and unexpectedly produced a good reaction, although the horse had been kept free from any fresh contagion. In this case also old-standing tubercles were found. Now both these horses might have been considered cured when mallein ceased to cause a reaction, but the subsequent test of one of them indicates that this failure to respond to the mallein was due to some temporary cause.

It would be important if we could ascertain the probable length of time that will elapse before clinical symptoms of glanders or farcy develop in horses that react to mallein. It is, of course, obvious that this will vary according to the surroundings and circumstances of each case, but we were hardly prepared for the long time our experience has demonstrated.

Nearly two years ago twenty horses were isolated because they had reacted to mallein. They still appear healthy, but when reinjected a very short time ago they all gave a good reaction, proving that they are still affected. Present appearances indicate that they are likely to become useless through their limbs becoming worn out before any signs of glanders or farcy appear. The apparently long time the disease slumbers has caused some horse-owners to express strong doubts as to the correctness of the action of mallein. This is scarcely to be wondered at. They see horses which science has marked as being affected with what has been so often described as a terribly dangerous and contagious disease fulfilling all the requirements of healthy animals for years without any evidence of this malady.

We know from old authors that under favourable circumstances horses would work for years even after some of the clinical symptoms had become developed. But little is known about this phase of the disease where the clinical symptoms are absent. That mallein which detects the disease also retards its progress appears a feasible theory.

Our old-fashioned ideas of the period of latency and the virulence of glanders have been very much upset by the use of mallein.

\title{
CLINICAL NOTES OF THREE INTERESTING CASES.
}

\author{
By William M. SCOTT, M.R.C.V.S., Bridgewater.
}

\section{STRANGLES IN THE HORSE, FOLLOWEI BY PYEMIA AND LATTERLY BY SEPTICAMIA.}

ANGINA, cynanche, adenitis, and pyogenic fever are a few of the more modern terms applied to that long-recognised and time-honoured equine disorder commonly known by lay and professional men under the everyday term of "Strangles."

Scientifically it is defined as a specific eruptive fever. When the disease runs its natural course, without any complications setting in, the case generally terminates favourably. But, unfortunately, some 
patients are placed in adverse circumstances such as barometric and climatic alterations, bad hygienic surrounding, bad food, etc., in short, through the many vicissitudes of life itself, this benign disease is driven from its own course, forced to don the sombre and deadly mantle, and death then often claims our patients as its own.

The case of which I am about to give a detailed account, was in the early part of the year attacked with strangles. He was housed for a few days, and as all seemed to be going on well the owner decided to turn him out to the moor. Painful to relate, the horse had not been seen (practically) from that day to the day I was called in. On arrival I was informed the horse was with difficulty brought home. After careful examination I found the patient in a very prostrate condition. Pulse 78 perminute and very weak, breathing quiet, but breath charged with a sickly odour. Temperature $994^{\circ}$. Mucous membranes injected-dirty reddish-yellow, sphincter ani relaxed, and during each respiratory act air was alternately drawn in and expelled per rectum. The mouth musty, tongue furred, abdomen tucked up, limbs swollen, extremities cold. At the most prominent parts of the body the skin had become indurated and shrivelled (bed sores), the result of lying. Bowels and kidneys in action.

In the submaxillary space there was a fluctuating swelling the size of one's fist. That I lanced, and a sickly-smelling pus was liberated. Taking the previous history with the present symptoms above related, I had no hesitation in coming to an early diagnosis; in fact all the symptoms pointed to a most typical case of septicæmia following strangles. The following morning the patient was a little better, pulse beats stronger and not so frequent. Temperature still subnormal. The obnoxious odour which was emitted from the breath, and from the bowels in the form of flatus, had subsided to a remarkable degree.

The third day I had a wire to see patient early, as he seemed worse. I found him lying stretched out on his left side and breathing rather heavy. He would lie in this recumbent position for a few minutes, then get up and look back to his left side and occasionally touch his abdomen behind the last rib with his nose; at times he would droop his head and walk round the box, always, as far as my observation went, having the left side towards the centre of the box.

After great care he would lie down, roll over on to his left side, and lie stretched out. Fearing the pain would kill by exhaustion, I gave him a minimum dose of morphia subcutaneously, and left an anodyne composed of camphor and chloral hydrate to be given if pain returned. A stimulant was rubbed into the abdomen.

The following morning I saw him again and found him, as I thought, progressing favourably. The appetite slightly improved, but nothing solid was given save a handful of grass at times. On taking the temperature I found the sphincter more contracted than I had ever noticed it, and the swelling in the hind legs gradually passing off.

The next day found the patient much the same as previously; if anything, slightly better.

The following day I had another urgent message. Found all the untoward symptoms exaggerated. The bad odour had returned with all its unpleasantness. The breathing hurried and difficult. The eye 
anxious and $\operatorname{dim}$ (this subject had only one cye), pupil dilated. The pulse numbered 90 per minute, weak and very irregular. On auscultating the chest over the region of the heart, that organ seemed to be tumbling about in a very disorderly manner, and I could distinctly hear (through the stethoscope) a sort of burring sound synchronous with the heart-beat. Dissolution was fast taking place. The same evening or early the following morning death had claimed him as its victim.

Treatment.-I have not considered it necessary to lengthen this article by giving a detailed account of the treatment. Suffice it therefore for me to say that I saturated the system with antizymotics - quinoidin and nitro-hydrocloric acid having considerable favour. The pain was counteracted by the drugs before mentioned. The nostrils steamed at the outset, the medium being medicated with turpentine. The surroundings carefully attended to as well as the general comfort of the patient. The atmosphere was saturated with creolin. As regards nutrients, milk and eggs, with Kepler's Cod Liver Oil and Malt Extract were lavishly utilised. The excretory organs were also attended to.

Post-mortem. - The following day I made a post-mortem examination. Rigor mortis only slight, the body rapidly decomposing. The double colon congested in patches, the small bowels healthy. The alimentary organs practically empty. The pyloric end of the stomach and 6 inches of the duodenum were the seat of discolouration, the hue being a pale yellowish-green with a tinge of blue in it. On cutting along the great curvature I left the discoloured part intact. The cuticular portion of the gastric membrane contained a number of bots, one-half of them being detached and lying dead in the fluids. On exposing the pyloric portion I found the remains of an abscess, the contents having been evacuated, and nothing remaining except a few threads of mucous membrane and a granulating irregular surface about 3 inches in diameter. The mucous membrane which I have already mentioned as lying across the ulcer was of a dark yellow colour tinged with brown. The duodenal mucous membrane presented an appearance identical with a piece of leather. The liver was soft and friable, and on cutting it a number of small abscesses were noted. The kidneys microscopically examined were found to be crammed with small emboli. The lungs, save for very marked hypostatic congestion, were healthy. The heart and pericardium outside seemed healthy. On exposing the cavities both sides of the heart contained an ante-mortem clot, each of which extended through the auricles right into their respective blood-vessels. The clot was fairly firm and of a pale reddish-yellow tinge.

Remarks. - Through the patient having been neglected and placed in adverse circumstances the strangles had become suppressed, and a metastatic abscess had formed in the coats of the stomach. Consequent upon that the animal became the subject of chronic gastric indigestion; with all its symptoms of unthriftiness and poverty. This gastric abscess was in my opinion the first to develop, of a pyæmic origin. The liver and kidneys secondarily became diseased through metastasis, and the animal became in every sense of the term a "cracked pot." It is worthy of note that no metastatic abscesses were found in the lungs.

Owing to the disintegrated condition of the blood by organisms, 
etc., combined with pulmonary congestion, an admirable opportunity was given for the formation of cardiac thrombi, which took place some fifteen hours before death.

When making this autopsy the thought struck me-what a mint of untold wealth is committed day and daily to the oblivious coppers of the knacker, what a fund of knowledge could be gathered if each and all the veterinary surgeons of this country kept careful notes of cases, and made autopsies whenever possible. It would bring us into closer relationship with the various and oft-perplexing symptoms made manifest during life, in comparison with those appearances presented after death. It behoves each one of us to do our level best to place this last superstructure of clinical medicine on a more scientific basis.

\section{JUGULAR HAMHORRHAGE CONSEQUENT UPON A PUNCTURED WOUND IN A HORSE.}

On the Ist of May of this year I was requested to attend a half bred chestnut mare which had met with an accident in the neck, and was bleeding with great profusion.

Previous History. - Ten days previous to my attendance this anima! had received a punctured wound in the neck, about 4 inches from the anterior extremity of the sternum and a little above the jugular furrow on the right side. This wound had been treated by one of those illiterate handy quacks who go about imposing upon the gullable public as well as the patients entrusted to their care.

Clinical History.-On my arrival I found the owner pressing the wound with a sponge to prevent the hæmorrhage, which when allowed its own course was very great. Constitutional examination showed the animal had lost a considerable amount of blood. The owner declared that she had bled over a stable bucketful. But taking into consideration the exaggerated estimate the lay mind is apt to form on looking at spilt blood, I should say the above-named quantity might be divided by two. On examination, the pulse at the submaxillary was very weak and small, the conjunctival mucous membranes very anæmic, and on the whole the animal pointed to considerable loss of blood. On taking note of the wound I found it situated, as previously mentioned, a little to the outside of the jugular furrow. On passing an exploring tube into the wound, while pressure was applied to the jugular further up the neck, I found it to extend $2 \frac{1}{2}$ inches in an inward, upward, and forward direction.

The calibre of the wound, as far as I could make out, would admit the entrance with ease of an extra-sized rectal dilating tube (Human). When pressure was applied to the vein above the bleeding practically stopped, when removed the hæmorrhage would commence with great volume, in a continuous stream and very dark in colour. Consequent upon bad treatment, and adding to the complexity of the case, the wound was very unhealthy.

Treatment.-The wound was thoroughly irrigated with an antiseptic (creolin); the hæmorrhage was checked by pressure upon the vein with a cork covered with lint and fitted into the jugular groove, this being kept in position by means of a strap tied round the neck, and fixed by taking advantage of the mane. The wound was plugged with carbolised lint, and the lips drawn together with two interrupted sutures. It was most interesting to note that if the 
patient was given sloppy bran no harm resulted, but if given a mouthful of hay or grass a slight strcam of blood would come through between the sutures. Consequently nothing but liquids and semi-solids were administered. Medicinally I prescribed sulphuric acid and quinine, three times a day. After about forty-eight hours I removed the plugging material, as the wound was manifestly septic. At the end of the wound a small clot of blood showed itself. The bleeding amounted to only about a half claret glassful.

I irrigated and replugged as before, and dusted the lips of the wound with iodiform. The pressure was removed from the vein.

The following day I had a wire to say the wound had burst out bleeding again. The patient had got her head down. All along I had had her tied up to a rack, and I attributed this as the cause of all the mischief. Redressed and plugged the wound.

I know it is bad surgery to pull about a wound if one desires the hæmorrhage to stop, but in this case I thought myself justified in so doing, considering that the wound was not altogether a septic. Furthermore, I took the precaution of guarding against a septic thrombus forming in the lumen of the vein by applying a hydrar. biniod. blister above and below the wound, and a few inches up the course of the furrow.

The following day the mare had slight fever, probably partly irritative, due to the blister; appetite fairly good, pulse stronger.

I plugged the wound twice more, and after that it seemed to be healing so well that I contented myself with having it syringed out three times a day with antiseptics. The vein was now felt to have become completely obliterated, the action of the blister having disappeared.

The next morning I was sent for, as the mare's neck had swollen all up the course of the vein to the angle of the jaw bone. This swelling was very hot, painful and slightly oedematous to the touch. The patient carried her head very stiffly. Continued hot fomentation was ordered, with a stimulating anodyne liniment to rub in. Lanced the swelling in several places to relieve the tension. A laxative was administered followed up with repeated doses of iodide and nitrate of potash. In three days time, after the acute symptoms had subsided, a blister was rubbed along the whole course of the neck.

Seven days after the application of the blister I saw the patient again, when $I$ found a fluctuating swelling 2 inches above the site of the wound and in the furrow. That I lanced, and removed about 4 ounces of pus. With very little more treatment the patient was turned out to grass, and now bids fair to make a good recovery.

Remarks.-There is no doubt to my mind if the animal had been treated antiphlogistically at the outset, with proper care of the wound, the inflammatory action should have been kept in abeyance, and the consequent sloughing, which penetrated the coats of the jugular vein and caused the hainorrhage, would never have occurred.

\section{ASCITES CAUSED BY A FIBROMATOUS HEPATIC TUMOUR IN A DOG.}

A few months ago an Irish terrier was sent to the infirmary for treatment, the abdomen having been noticed by the owner to become 
seriously swollen and tense. The dog had not been well for quite two months previously. When first seen by me the abdominal wall was so tense and hard as to resist considerable pressure. The various diagnostic methods did not seem necessary to arrive at a pretty accurate conclusion, so that I directly made preparations to tap the abdomen. The seat of operation was a little to one side of the median raphe, and close to the umbilicus. The hair removed, the skin was disinfected with an antiseptic, a small incision made in the skin with lancet, and trochar and canula inserted. The fluid withdrawn was highly sanguineous, so much so, indeed, that the lumen of the tube at intervals became blocked with coagula. Care was taken not to allow all the fluid to drain away at once. At this, the first tapping, $3 \frac{1}{2}$ pints of fluid was removed. The patient had a bandage placed round the abdomen to give support. After collapse of the abdominal cavity one was in a better position to examine the various organs. I may here state the skin and mucous membranes presented an icteric appearance, the pulse was very weak, but the appetite fairly good. Distinct swelling was noted over the region of stomach and liver, but particularly on the right side. On pressing from below upwards behind the last ribs, the patient evinced symptoms of pain. The heart was examined as well as the lungs, but no evidence of organic disease was noticed. The cardiac sounds were weak. I gave it as my opinion that we had to deal with some obstructive liver disease, the nature of which I would not pretend to say. Treatment at this stage consisted in the administration of a small calomel pill followed up by doses of pot. iodide, but, considering the depressing influence these potassium salts have upon the cardiac and nervous systems, I deemed it good policy to give also some ammon. carb. and nux vom. Paracentesis abdominis was repeated in six day's time, the fluid having reaccumulated. The fluid was now not so sanguinous, but more of a straw-coloured hue. About 2 pints were removed at this tapping. The patient's appetite remained fairly satisfactory. The therapeutical agents previously mentioned were still persevered with, with the addition of dialysed iron. In the course of a few day's time the fluid was noticed to be increasing again. Seven days exactly from the time of last tapping, i performed the operation again. This time the fluid was not so clear as previously, and the quantity withdrawn was $2 \frac{1}{2}$ pints. Seeing the slow progress made by the patient, I consulted the owner as to the advisability of giving a lethal dose. To this he acquiesced, although with some reluctance.

Post-mortem.-On cutting open the abdominal cavity a quantity of fluid escaped. The parietal and visceral peritoneum, instead of being clear and glistening, was dull and opaque. Lymph and the other products of inflammation were conspicuous by their absence, and there were no adhesions except at a part in the small gut, where one fold of bowel was adherent to its fellow. The stomach healthy. The liver was found to weigh I $9 \mathrm{oz}$, and was remarkably large in proportion to the size of the animal. The central lobe was the main seat of the disease, on section with the knife it cut like a piece of tendinous tissue, and practically the whole of the liver tissue had here been replaced by this new growth. One or two blood-vessels were noted on the surface of the section, their mouths standing widely open. The other lobes 
were healthy outside the margin of the tumour. Pieces of the tumour were hardened in spirit, mounted in the usual way, and examined microscopically, which showed that the tumour was composed of fibrous tissue. The heart was healthy, but seemed loose and flabby. Kidneys soft and friable, apparently undergoing fatty changes.

\section{SCLEROSTOMA ARMATUM IN THE SPERMATIC CORD.}

\section{By W. Selborne Worthington, M.R.C.V.S., Wigan.}

WHILE castrating a grey two-year-old cart colt on 3 rd June, I came across a specimen of the agamous form of the sclerostoma armatum in a rather uncommon position.

On the inner surface of the posterior or fibrous portion of the right spermatic cord, a little above the globus minor of the epididymis, was a tube composed apparently of white fibrous tissue, about threesixteenths of an inch thick and one and an eighth inch long, situated immediately beneath the serous covering of the cord, and standing out distinctly above the surrounding level. The tube was disposed in an oblique direction downwards and backwards, terminating at its lower extremity about three-quarters of an inch above the globus minor. It was open at both ends and contained an agamous sclerostoma armatum of about the same length. The parasite was undergoing degenerative changes, being very soft and friable.

I sent the specimen to Professor Stockman who examined it, and identified it as the agamous form of the sclerostoma armatum. The colt, though in poor condition, is and has been apparently in good health, and the farm on which he has been reared has never been suspected of harbouring these parasites.

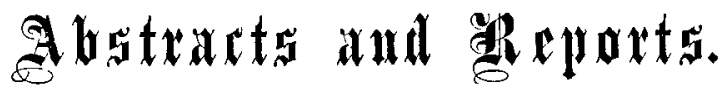

\section{MEAT POISONING.}

IN the spring of the present year, in the Canton Thurgau, numerous persons fell ill after having partaken of pork that had been smoked. The flesh, it was alleged, came from animals that had been killed while seriously ill, the symptoms exhibited being redness of the skin and gastro-intestinal catarrh. Seven persons who had partaken of this flesh were during the following day attacked with gastro-intestinal catarrh, and one child, aged four years, died after two days, with profuse diarrhœa and cramp-like contractions.

No symptoms of disturbance were produced in animals fed with the flesh in question, but, on the contrary, the intraperitoneal injection of cultures obtained from the discharges of one of the patients and from the flesh were always fatal. In the discharges from the patients and in the suspected flesh there was present a short motile bacillus with rounded ends. The case 